\title{
Metastatic Angiosarcoma
}

National Cancer Institute

\section{Source}

National Cancer Institute. Metastatic Angiosarcoma. NCI Thesaurus. Code C8708.

An ang iosarcoma that has spread to another anatomical site. 